\title{
INEQUALITIES FOR CERTAIN FINITE DIFFERENCE AND SUM-DIFERENCE EQUATIONS
}

\author{
B. G. PACHPATTE
}

Abstract. The aim of the present paper is to establish some basic finite difference inequalities which provide explicit bounds on unknown functions. The inequalities given here can be used as tools in applications in the theory of certain finite difference and sum-difference equations.

Mathematics subject classification (2000): 26D10, 26D15.

Key words and phrases: Inequalities, finite difference and sum-difference equations, finite difference inequalities, explicit bounds, two independent variable generalizations, nonincreasing function.

\section{REFERENCES}

[1] D. Bainov And P. Simeonov, Integral Inequalities and Applications, Kluwer Academic Publishers, Dordrecht, 1992.

[2] F. S. DeBlasi And J. Schinas, On the stability of diference equations in Banach spaces, An. Sti. Uni. "Al. I. Cuza" Iasi, Sect. I 20 (1974), 65-80.

[3] A. Mate AND P. NeVAI, Sublinear perturbations of the differential equation $y^{(n)}=0$ and of the analogous difference equation, J. Differential Equations 53 (1984), 234-257.

[4] D. S. Mitrinović, Analytic Inequalities, Springer-Verlag, Berlin, New York, 1970.

[5] B. G. PACHPATTE, Discrete inequalities in two variables and their applications, Radovi Matematici 6 (1990), 235-247.

[6] B. G. PaChPatTE, On certain new finite difference inequalities, Indian J. Pure Appl. Math. 24 (1993), 373-384.

[7] B. G. PaChPATte, Some new finite difference inequalities, Computers Math. Applic. 28 (1994), 227-241.

[8] G. PAPASCHINOPOULOS, On the summable manifold for discrete systems, Math. Japonica 33 (1988), 457-468. 